\title{
Discussion on Teaching Reform Exploration for International Business Negotiation Based on Intuitional Experience
}

\author{
Xiaqing Liu" ${ }^{1,{ }^{*}}$ and Li Zhang ${ }^{1, b}$ \\ ${ }^{1}$ Shandong Technology and Business University, Yantai, Shandong, China 264000 \\ aliuxiaqing111@163.com, ${ }^{b} 332853225 @ q q . c o m$,
}

\begin{abstract}
Keywords: Intuitional experience; Discussion teaching; International business negotiation;
\end{abstract} Teaching reform

\begin{abstract}
This paper studies International Business Negotiation teaching reform from the perspective of Bergson's intuitional experience education philosophy. On the basis of present situation of International Business Negotiation teaching, this paper integrates intuitional experience into discussion teaching practice, which provides an innovative research angle for International English Teaching, realizes connected knowledge digesting and absorbing, and further cultivate learners' cooperative awareness.
\end{abstract}

\section{Introduction}

Discussion teaching have been applied in International Business Negotiation for quite a long time. However, teaching research and practice mainly emphasize on the connotation, characteristics, and operation sequences of discussion teaching. Application of discussion teaching to different courses pays more attention to diversity of courses and participants. Few researchers study International Business Negotiation teaching from the perspective of intuitional experience. Taking institutional experience of learners towards unfamiliar knowledge into consideration is a significant try. Many scholars hold the idea that teachers should be the leader at the very beginning of the knowledge introduction, no matter in the "duck-stuffing" type of teaching or in discussion teaching, for the teacher should transfer knowledge information. In that case, learners' thought will be limited and such discussion cannot invoke learners' thinking potentiality and participant enthusiasm. Discussion teaching based on intuitional experience let the learners discuss and raise questions, based on which teachers lead the learners achieve teaching objectives in a circulation rising way.

Studies on International Business Negotiation teaching have become increasingly popular, especially with the implementation of ESP teaching, which mainly cover four areas, namely, negotiation results, negotiation behavior, negotiation theoretical model, and negotiation strategies. Teaching practices for International Business Negotiation are influenced by pragmatics, and qualitative researches are main paradigms. This paper integrates intuitional experience, discussion teaching, and teaching practice, and puts forward a feasible model for International Business Negotiation teaching.

\section{Literature Review}

Discussion Teaching. Discussion teaching model means a teaching method that learners take part in the class discussion and interaction between teaching and learning objective are realized with the lead and enlightenment of teachers. Compared with jug-and-mug teaching, it emphasized on interaction and communication between teaching and learning. Chinese ancient educator Confucius passed on knowledge by means of discussing questions with learners. Ancient Greece philosopher Socrates did it too, which was named after midwifery. In 1919, Britain professor Kane put forward the concept of discussion teaching model clearly, which is similar to problem-based learning, PBL for short, because both of them emphasize on the communication between teachers and learners. Problem-based learning was proposed by American neurology professor Barrows, which has become one of most 
popular teaching method worldwide. It is the same case in China. A large number of scholars both abroad and at home conduct further researches on discussion teaching. Zhou et al. divided discussion teaching into guide-teaching mode and open-teaching mode, and held the idea that guide teaching mode is composed of teaching-discussion-conclusion and comment three steps. [1] Israa M. Alkhasawneh, et al. measured the PBL teaching method with the objectives of the third year students majoring in Nursing in a public university in Jordan. [2] It was revealed that learners in the PBL group improved a lot while students in lecture group fell behind in problem solving and self-orientation study. [3] Discussion teaching are applied in various course teaching, such as philosophy, literature, science, engineering, medicine and management, and have achieved a lot of accomplishment.

Intuitive Experience. Intuitive experience was proposed by a French psychologist who believed that intuitive experience integrated ideas from psychology, philosophy, aesthetics, logic and science. It is a way of thinking, a cognitive approach, and a holistic epistemology. Therefore, intuitive experience has great significances for education reform. Nowadays, scholars introduce intuitive into teaching, explore the importance and significance of intuitive to learning. Yang believed that intuitive cultivation needs course reform and requires learners enhance intuitive thinking capability based on increasingly improved logic thinking. [4]

\section{Current Situation of International Business Negotiation Teaching}

At the end of $20^{\text {th }}$ century, there are increasing needs for face-to-face verbal communication ability in business activities. In that case, International Business Negotiation is taken as an independent course. Gradually, international business negotiation in English is regarded as an important technical course for International Business Operator certificate.

International Business Negotiation teaching abroad started from 1960s, and underwent three developmental phases, namely, independent phase, interdisciplinary formation phase, and rapid development phase. The first phase is around 1960s, and is characterized by the publication of Negotiation Notes, which was described as covering numerous theories and practices. At the end of 2006, Andrea Schneider and Christopher Honryman published The Negotiator's Field-book, which encompasses existing thoughts and concepts for business negotiation. The second phase is characterized by Alternative Dispute Solution initiated by Christopher Honryman, James Coben and Giuseppe De Palo. After that, almost all the law schools and business schools in America set up a negotiation-related course. In North America and Europe, a cross-cultural negotiation teaching system was established and scholars with rich business experience and business elites were invited to deliver lectures to them. For instance, Trompenarre Hampden-Turner (THT) is a typical cross-cultural management research center.

International Business Negotiation studies and practices at home are conducted from three dimensions. The first research dimension think that the teaching outcome is to improve the pragmatic capability of learners in business environment, which are based on Lado's foreign language level division theory, Chomsky's linguistic competence, Hymes's context theory, and Bachman's pragmatic competence. They strongly believed that pragmatic competence cultivation together with business negotiation language structures should be included in the teaching practice. The second dimension pays more attention to cross-cultural communication ability cultivation and cross-cultural pragmatic competence, which are based on Wen Qiufang's cross-cultural competence cultivation, He Zhaoxiong's cross-cultural pragmatic linguistics achievements, Austin's speech act theory, Grice's conversational cooperative principle, Leech's politeness principle, and Brown \& Levinson's face theory, and Verscheueren's adaptation theory. Vast majority of textbooks include a chapter with the topic of cross-cultural negotiation. The third dimension emphasizes on learner-centered curriculum provision and class organization. Advocates for this dimension agree with Ellis's opinion that learner-oriented teaching activity should pay attention to interaction between teachers and learners. The advocates praise highly about case-based teaching, program-based teaching, and task-based teaching. 


\section{Discussion Curriculum Concept Based on Intuitive Experience}

Knowledge Digestion-absorption Path Construction. Intuitive experience has the functions of direct perception, fast discovery, and distinctive prediction, and can motivate learners' creativity. Teachers should change inherent concepts about teaching and learning, and realize the effect that class learning starts from students and return to them finally. Generally, International Business Negotiation is set up after preposition courses such as International Trade Theory and Practice, Business English Writing, International Business Law, Business Spoken English. Learners have established a knowledge systematic frame. In this case, learners rely on their intuition, raise questions, after being denied or verified, and modify the frame they have already established, which is the process of knowledge digestion-absorption path, as is shown in Fig. 1.

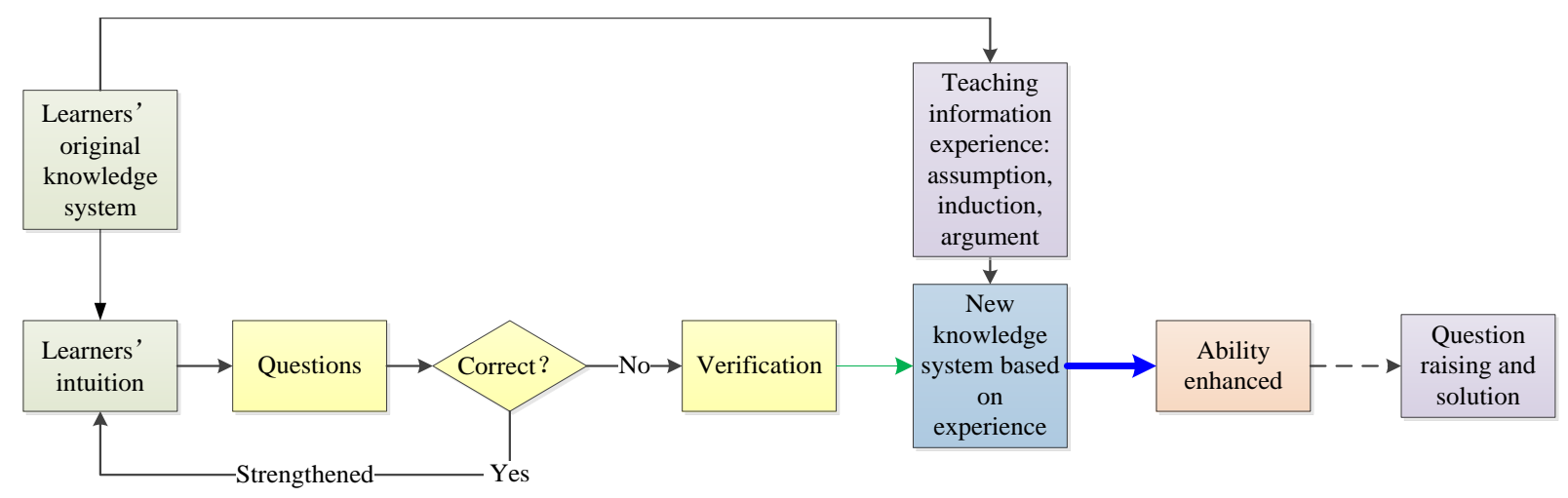

Figure 1. Knowledge digestion-absorption path flow chart

Circulation Discussion Teaching. In consideration of inadequate class participation, a new spiral teaching model is proposed as following: students' making statement-circulation discussion - teacher's comment-knowledge digestion—students' make statement—knowledge assumption. An easy class context is set up to stimulate learners' awareness and interests to participate in the discussion and question exploration. Students become active learners instead of passive learners. They are cultivated to capture new information, generalize and summarize pieces of information, focus on priorities, cooperate with teammates and deal with problems flexibly.

Effective Motivation Model Construction. An effective motivation model should be set up to inspire learners' active thinking and participation. First of all, teachers should establish equal and free class atmosphere where students can speak out their thinking freely. Secondly, in view of diverse characters and different levels of knowledge foundation, introvert and relatively slow students should be encouraged to present their thinking. Next, with the further discussion, teachers motivate students by raise thought-provoking questions. At this stage, teachers can often harvest a lot of questions and answers beyond their expectation. At last, teachers summarize the question and review the discussion process, which strengthens students' understanding and elicit the next round discussion. The motivation model is shown in Fig. 2.

Intuitive Discussion Model Implementation. If the class effect is significant, then it can be modified in accordance with the characteristics of each course and expanded into the other course teaching. In view of such problems as rigid and conservative teaching model, single form, indolent thinking habit, we combine intuitive experience and discussion teaching together. Take commodity price negotiation for example. A short video about the authentic context in an international business company is used as a lead-in for the topic. Students are encouraged to speak out their thinking, understanding, and questions about the offer, counteroffer, and bargain process based on their intuitive experience. Notice that the questions proposed by students cannot be limited to conclusive questions or statements. They are expected to raise such explorative questions as "I want to know / I wonder what/ why/ how......". The students speak later may choose to answer the raised questions or raise a new question or put forward their ideas from a different view point. After a round of question 
raising and discussion, teachers make comment and conclusion, and then present price negotiation paradigms, offer and counteroffer routines, and price negotiation strategies and tactics systematically. In this way, students are willing to accept those theories because they want to know how their ideas are identical with or different from those of the experts. When the knowledge is absorbed, then another question can be raised to evoke the new round discussion. In this way, the thinking scope will be broadened and deepened, and students can learn the essence of the questions, in order to analyze and solve practical problems flexibly and professionally.

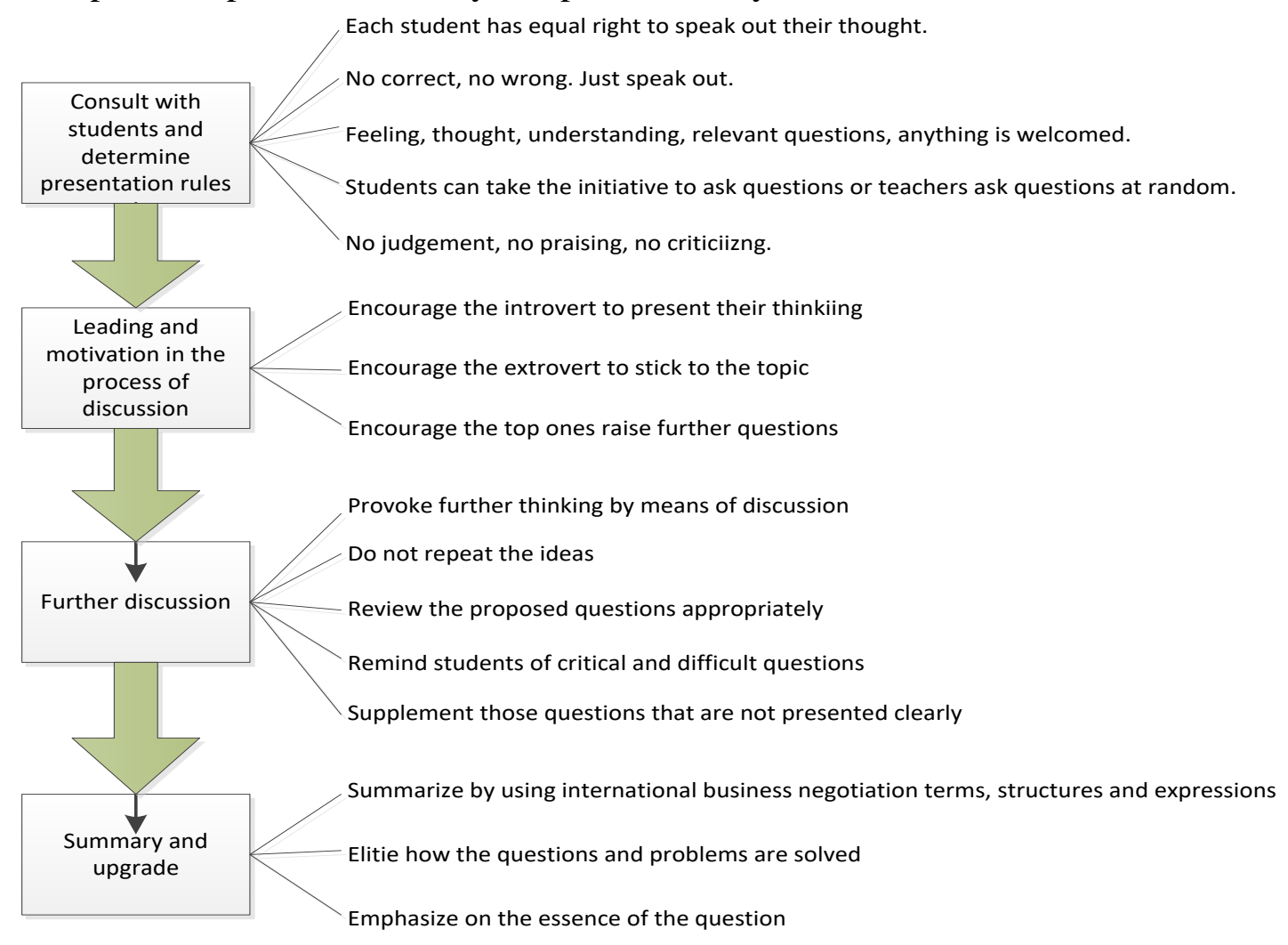

Figure 2. Effective motivation model chart

\section{Reform Practice of International Business Negotiation Teaching}

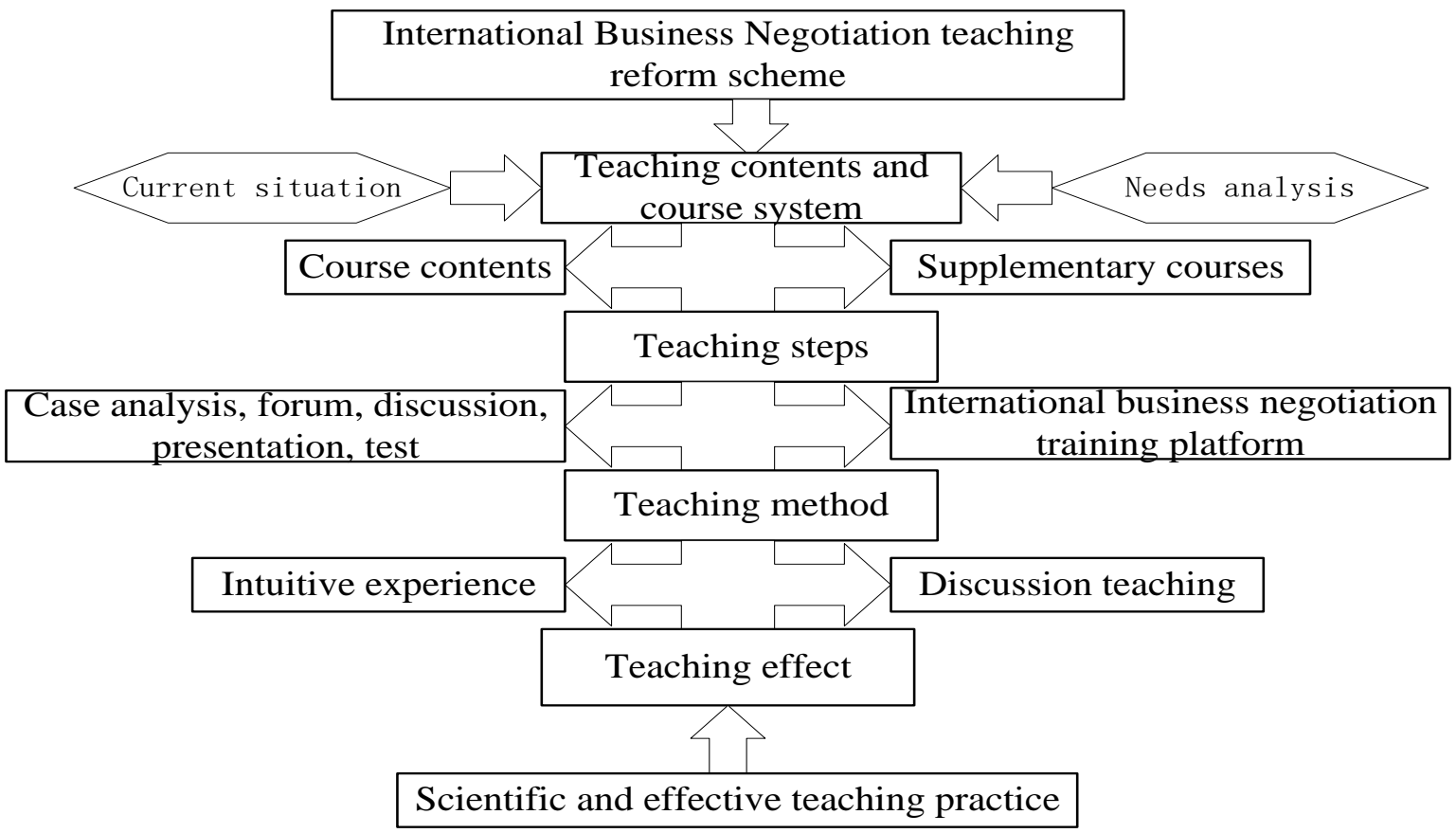

Figure 3. International Business Negotiation Teaching practice flow chart 
International Business Negotiation is an interdisciplinary course and full of expertise and practical requirements. On the basis of intuitive experience teaching model, the course teaching design starts from the concept, process, strategy, and tactic of international business negotiation, establishes statement rules, and encourages students to raise questions and answer questions. In this way, students are led to thorough thinking. A period of time is left after the comment for students to digest, and repeat the spiral process. Fig. 3 illustrates the steps for reform practice.

There are three key factors influencing teaching practice. At first, changing and updating teaching concept is the most fundamental thing. If a teacher upholds authority and utility tightly, and emphasizes imitation and paradigm, then this practice cannot be implemented well. Intuitive experience education philosophy respects curiosity and interests, expands learners' view, and explores students' risk taking ability. Secondly, teaching design to class is as designing to architecture building. Teaching design reflects a teacher's thinking, thinking process, and teaching art, and it is a systems engineering. In this case, scientific teaching design is a key matter for teaching reform and practice. Thirdly, the teaching practice put forwards high requests for teachers, which requires that teacher should not only know well about teaching contents including solid theoretical knowledge and rich practical operation experience, but also be capable of transforming contents into effective course designing. Therefore, high quality teacher training and recruitment is needed and necessary for this teaching reform implementation.

\section{Summary}

Intuitive experience based discussion teaching for International Business Negotiation is followed by the process of presentation, discussion, comments, information digestion, presentation, and information absorption, which can invoke the enthusiasm and initiative of thinking questions, enhance students' information acquisition ability, inducement thinking ability, flexibility and cooperative capability, which will in turn improve the learning effectiveness. The proposed teaching model in this paper regards teachers as an external thrust for the system operation, this thrust will exert catalytic effect, and bilateral power of teaching and learning will generate finally. This model emphasizes the interactive communication between teachers and students, which can raise learning enthusiasm, and lay the foundation for life-long learning and professional or career development.

\section{Acknowledgements}

This paper is sponsored by Teaching Reform Project of Shandong Technology and Business University (No. 11688JXYJ2015009).

\section{References}

[1] J. X. Zhou, H. Su, Z. G. Shi, Application of discussion teaching method in college teaching, Journal of Higher Education Research. 9 (2008) 55-57.

[2] I. M. Alkhasawneh, M. T. Mrayyan, Charles Docherty, Safaa Alashram, Hamzeh Y. Yousef. Problem-based learning (PBL): Assessing students' learning preferences using vark, Nurse Education Today. 28 (2008) 572-579.

[3] E. Choi, R. Lindquist, Y. Song, Effects of problem-based learning vs. traditional lecture on Korean nursing students' critical thinking, problem-solving, and self-directed learning, Nurse Education Today. 34 (2014) 52-56.

[4] K. L. Yang. On roles of intuitive thinking to undergraduate knowledge, Modern Science, 18 (2010) 74. 